\title{
Students' Perceptions of a Learning Support Initiative for b-MOOCs
}

\author{
https://doi.org/10.3991/ijet.v15i21.17153
}

Shurong Zhao $\left.{ }^{\bowtie}\right)$, Junxia Song

Shandong Women's University, Jinan, China

cathyesdwu.edu.cn

\begin{abstract}
Blended learning based on MOOCs (b-MOOC) has become a new and wide-spread approach to combining internet technologies with face-toface instruction in higher education. In the implementation of b-MOOCs, learning support or scaffolding proves to be essential and determines to some extent the success of blended learning, while available literature shows lack of research on it. Aiming at exploring a feasible learning support approach for bMOOCs in practice, this study constructed a support framework with four key elements of resources (R), interaction (I), strategy (S) and evaluation (E) support, briefed as RISE, and implemented it in the Business English course in a Chinese university. A survey and semi-structured interview were conducted to make clear its effects, the perceptions and expectations of students. It shows that the RISE support initiative got wide recognition and resulted in various improvements, promoting learning autonomy, improving learning strategy, increasing interaction and time devoted. As to suggestions, more targeted and higher degree of support is expected by learners and they show preference for face-to-face instruction and suggestion is raised that the proportion of face-toface section should be no less than the online part. The results of this study may offer practical reference in b-MOOC design about how to support learning process of students and what components and methods are effective.
\end{abstract}

Keywords-B-MOOC, learning support, perception, RISE framework

\section{$1 \quad$ Introduction}

The explosive development of internet information and communication technologies is transforming the world. In the higher education context, blended learning (BL), as an approach integrating online learning and face-to-face interaction, proves to be an effective and low-risk strategy for meeting the challenge of the transformational changes that technological developments bring to higher education [1-2]. It is described as the "new normal", the "future" of education and in practice it got widely used and explored in recent decades. The explorations to pursue appropriate design and satisfactory outcome never stop and even appear to proliferate over time, especially when new forms of BL emerge. 


\subsection{B-MOOC, a new and wide-spread BL approach}

2008 saw the offering of the first MOOC (massive open online courses), which is defined as online course predominantly produced by elite university with the promise of providing free high-quality education to an unlimited number of learners [3]. Characterized as an approach of anytime, anywhere learning, MOOCs offered students the opportunity to complete their studies at their own pace [4]. In the initial stage, MOOCs were classified into X-MOOCs and c-MOOCs, with the former focusing on knowledge duplication [5], and the latter on knowledge creation. x-MOOCs and cMOOCs got limited research attention and the situation became totally different with the emergence of another type, the b-MOOCs.

In 2014, Harvard university initiated the practice of combining MOOCs with campus face-to-face learning activities, which started a brand new and popular approach [6]. The BL approach based on the digital media consisting of MOOCs is known as blended MOOCs (b-MOOCs), also referred to as "blended MOOC 3.0" or "distributed flip" model [7]. b-MOOCs can bring together the respective benefits of online learning and face-to-face interaction, lead to student-centered learning, and resolve existing problems of lack of effective communication and high dropping-out rate of MOOCs [8]. In order to adapt to the new approach, especially the classroom component, the scope of MOOC also changed slightly, from massive audience to limited or small recipients, or targeting both a group of enrolled students on campus and global participants [9].

\subsection{Learning support, an essential element of b-MOOCs}

For instructors and researchers, in the process of implementing the new learning paradigm of b-MOOCs, some common and recognized principles should be followed. A key principle is that they need to shift their emphasis from delivering knowledge to unpacking the content for deeper levels of learning [10]. The evolved design of BL appears to be the essential issue, which streams instruction to be learner-centered instead of being teacher-centered, with teachers' role transforming from lecturers to learning promoters or facilitators, urging students to get engaged in their learning, and at the same time offering support and encouragement to them [11]. Graham et al suggested a BL framework with three crucial elements, strategy, structure and support [12]. As stated in [13], successful BL requires a well-devised plan that must include a theoretically sound instructional model, high-quality faculty development, course development assistance, learner support systems, and on-going formative and summative assessment plans. Informed by these research findings, support proves to be an essential element in BL design [14].

For learners, the complicated learning experience of pursuing knowledge and competency acquisition back and forth between the two worlds of online learning and campus learning does constitute challenge and calls for particular strategy and skills [15]. It requires them to be responsible for their learning and adapt to the new paradigm. Therefore, learning support becomes essential in meeting the needs and solving the problems of learners. It is found that graduate students preferred BL to face-to- 
face instruction due to extra support from instructors [16]. On the other hand, BL does not naturally translate into necessary and appropriate support. Some reports showed that one of the major reasons for many students' dislike of or even dropping out of BL course lies in insufficient support or scaffolding available [17-18]. Low degree of support might lead to low engagement and experience of frustration [19].

Despite the significant role of learning support in BL design and for learners, it is insufficiently investigated, let alone in the b-MOOC setting. As stated in [20], the literature review listed top ten research topics on BL, including instructional design, attitude, exploration, learning achievement, comparison, technology, interaction, demography and career development. Learning support was not among them and was hardly mentioned in the reviewed articles [21]. The available limited research on support are mainly about institutional support for course redesign and planning, on technical support and on support for teachers [1] [12] [22]. Therefore, there needs to be adequate and in-depth research on learning support to facilitate learning achievement and success, and to offer reference and guideline for instructional practice, particularly in the MOOC-based BL setting [22].

\subsection{RISE learning support framework}

In order to explore the learning support in b-MOOC, this study tries to construct a learning support framework and test its effects. Previous researches explored the principle, content, method and media of learning support [23-24], which offered foundation for the establishment of support framework of this study. As stated in [25], learning support refers to all those measures taken by facilitators to encourage and enhance learning. To be specific, it may include meeting all the needs learners may have, covering preparatory tests, study skills, access to seminars and tutorials, and so on. These support measures are adopted online and offline, among students, teachers and content, connecting and bridging those pairs or elements [26]. As stated in [24], in the BL context learning support plays an essential role and it should be cognitive, emotional and systematic. As to the elements of learning support, there are three aspects, including support for digital competency of students, support for interaction, both online and in classroom, and offering feedback to support learning [27]. As stated in [28], support encompasses several aspects, including offering challenge, feedback and encouragement, providing instruction and help in task performance, presenting clear expectations and guidelines. Support can be offered through a variety of media or methods, for instance, instant messaging, email, telephone, or web-based tutorials and materials [29].

Informed by the previous studies and to explore an approach to learning support, this study constructs a framework of learning support in the MOOC-based BL context. It consists of 4 elements: resources support (R), interaction support (I), strategy support (S) and evaluation support (E), briefed as RISE hereinafter.

Resources support. Resources act as the major source of support for learning. In the b-MOOC course, learners' learning activity depends mainly on the series of online videos, on various platforms or social media outlets [30]. In this sense the quality of MOOCs and the degree to which the MOOC resource matches the learning objectives 
of this particular course turn to be important elements for teachers to consider when choosing the appropriate MOOC resource. When designing the online courses, thoughtful decisions should be made on what contents can be best delivered on the Internet and what can be best delivered through face-to-face section [13]. According to the 'best of both worlds' view [31], teachers need to bear in mind these resources will be the material the student should be responsible for and be able to control.

Interaction support. Social interaction proves to be important for learning, because in the process of communication and interaction, high level mental functions such as induction, comprehension and critical thinking are practiced [32]. As of peer interaction, when learners join social community, communicate with other members and develop relations, social presence occurs. In this sense meaningful and subject-related interaction will benefit acquisition and enhance learning in BL [33]. From another perspective, frequent student-faculty interaction will promote motivation, engagement and satisfaction of learners, and ultimately lead to satisfactory learning result.

Strategy support. In the context of BL, pursuing knowledge back and forth in the online and face-to-face learning environment constitutes challenges for learners, especially those with no previous experience. These challenges, if not properly addressed, will result in sense of frustration and loss of confidence in learning. Therefore, teachers should offer ongoing and differential strategy support to learners at different stages of learning, providing strategy suggestions on learning of online videos and preparation of classroom activities, as well as tactics to coordinate online and face-to-face knowledge acquisition. And particular strategy and skills of self-regulation should also be instructed and trained. Furthermore, learners need to manage all the available resources such as learning time, environment, assistance from instructors and peers in BL context, therefore training of self-regulation strategy is necessary and will enable learners to manage effectively their learning activities [34].

Evaluation support. Of all the active learning methods, testing is the simplest to be identified as an effective strategy [35]. The assessment of attendance and involvement proves to be the salient factor in promoting engagement and knowledge acquisition. In b-MOOC context, where students watch the videos in advance, teachers will have more time to monitor the learning performance of students and provide adaptive and timely feedback. Evaluation of pre-class videos watching, classroom and forum discussion participation, as well as after-class task completion, may effectively urge learners to finish their learning tasks, to join actively the discussion. From another perspective, it's encouraging to design differentiated assessment and offer the learners the option to choose among a variety of methods of assessment one which can best demonstrate their learning [27]. During this process of evaluation, learners gain access to see their own progress and achievement. Therefore, it does make sense for instructors to design sustainable, formative and verified evaluation systems in the bMOOC context.

\subsection{Research questions}

This research, based on findings of extant study, addresses the lack of exploration on learning support in the setting of BL based on MOOCs. The RISE framework emphasizing 4-element learning support for b-MOOCs was designed and 
implemented in a higher education institution in China and data were collected to verify its effects. It is hoped the findings of this study will present first-hand information and experience for other practitioners and provide some reference in their BL design. This study addresses the following research questions:

RQ1. What are the perceptions from students of the b-MOOC approach with RISE learning support?

RQ2. What are the students' perceptions of the four elements of RISE learning support framework?

RQ3. What are the expectations and suggestions of the b-MOOC learning support system from students?

\section{Research Methodology}

\subsection{Participants and context}

This study, in an effort to explore an appropriate support initiative, implemented the RISE support framework with detailed measures in the Business English course for a cohort of 87 undergraduates. The approach was surveyed and measured in order to test its effectiveness and find out recommendations for future research and application.

Totally 87 undergraduate students aged from 19 to 22 participated in this research. They are in their third-year study of Business English major in a higher education institution in China, with no previous experience of BL.

Business English is a core course for Business English majors, registering 2 credits, the content of which is delivered through the illustration and discussion of some business topics with one topic for each chapter. The MOOCs of Business English in this study were put in Zhihuishu, one of the officially certified and widely-used MOOC learning management system (LMS) in China. It tracks and records the whole learning process of students. Discussion forum and various assessment tools are offered. All these offered extra data which supplemented survey and interview and facilitated the verification of RISE framework.

The BL approach with RISE learning support measures has undergone implementation of 3 cycles, while the students in each cycle are different. During this iterative implementation process, feedback and reflection were collected and used for revision of course design. As stated in [36], effective designs will evolve only through cycles of practice, evaluation and reflection. The teachers in this study command the course content as they designed and recorded the MOOCs themselves rather than use others' MOOC resources and have obtained experience of b-MOOC instruction. The description of instruction process is based on the latest round of approach, lasting a whole term, from September to January of the next year. 


\subsection{Implementation of RISE support framework}

Taking into consideration the nature and characteristics of the particular teaching context, the guideline and principles of RISE framework were specified, supplementing detailed measures, and implemented throughout the whole term, as what is shown in figure 1.

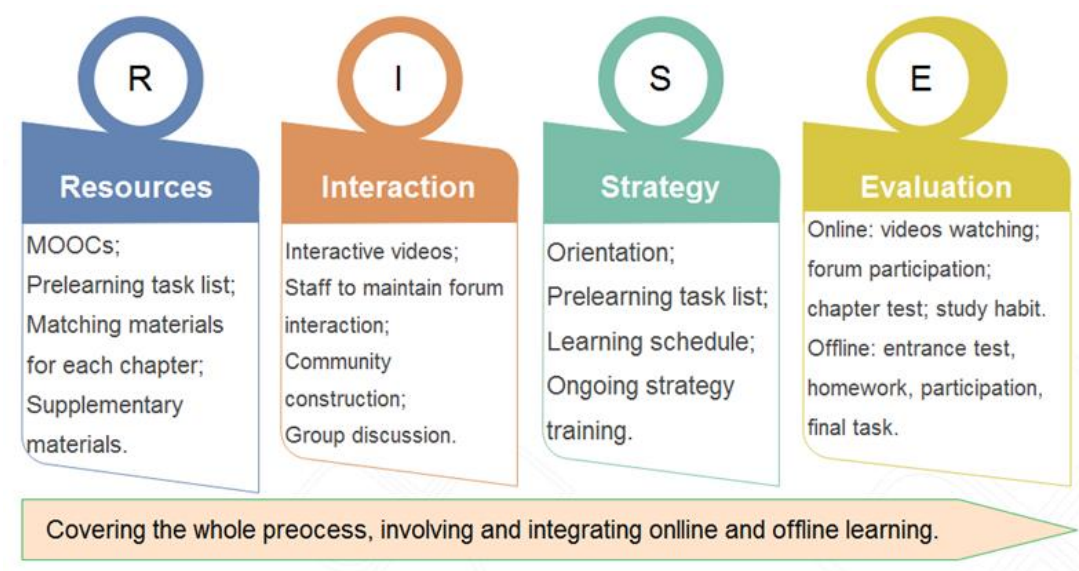

Fig. 1. Implementation of RISE framework in Business English course

Resources support: The BL in this study was carried out based on the online MOOCs of Business English designed and made by the teaching team themselves. This approach, which has become a wide-spread choice for many teachers in higher education institutions, solves the problem of taking time to get to know the unfamiliar course content offered by teachers from totally different education environment. Additionally, it results in higher possibility of seamless integration of online and offline learning activities. The MOOCs for Business English in this study consist of a series of structured short videos with embedded questions, followed by matching tests at the end of each chapter. In order to integrate online and face-to-face learning activities and offer assistance for the learning of MOOCs, 12 pre-learning task lists, matching all the 12 chapters of the course, were distributed to students before their learning of each chapter. These lists cover the background knowledge, learning objectives, structure and emphasis of each chapter, and present various tasks such as blank-filling or short answer questions for students to complete while watching the videos online. The resources suite includes also the matching teaching materials for each chapter, for students' reference, and for teachers' use when organizing discussion during face-to-face instruction.

Interaction support: The interaction facilitation of this study, a two-fold approach, covers both online and face-to-face communication. For online dimension, the videos were interactive with embedded questions for students to answer, appearing about every 5 minutes, which can't be skipped. In order to guarantee timely response to students' questions and prompt help, one member of the teaching team 
took up the responsibility of maintaining online discussion, answering questions and offering help. She posted a topic relative to the content learned every day on the forum and acted to encourage discussion and debate there. For the face-to-face component, the instructors assisted in the initial class the configuring of the individual and group learning activities and learning community construction. And a "works doctor" program was launched in a one-on-one form every other week. In that program instructors met students one by one to analyze and discuss their comprehensive works, for example the company profiles students drafted after finishing the learning of chapter 1 titled company profile, offering individualized instruction.

Strategy support: At the beginning of the term, there was an orientation section. The nature and characteristics of BL were introduced, followed by relative learning strategy suggestions on how to adapt to BL and make full use of online and offline resources. Added to that, the objectives of learning and schedule of the whole term were presented, in order to make them fully prepared for this new form of learning and urge them to draft their own schedule and develop their respective strategy. In the process of learning follow up, the strategy was discussed and reinforced until the improved one took form and stabilized. Also, the pre-learning task lists offered indication of efficient and effective tactics to conduct the online and face-to-face learning.

Evaluation support: A formative evaluation system was designed, also falling into online and offline sections. For the online part, it combines 4 parts: interaction marks, study habit marks, scores of tests for each chapter and video-watching marks, with their respective weights in the final marks. To get the interaction marks, students should participate actively in the forum discussion. And if they finish the online learning in a very short time, for example only at the end of the term, they can't get the study habit marks. In this way, students are guided to gradually form their appropriate and beneficial pace of study and use the forum actively. For the offline section, there was an entrance test at the beginning of each face-to-face class, designed to check the fundamental concepts or terms students have just learned in the online videos, so as to bridge the online and offline learning. Furthermore, participation in the group discussion and performance in the comprehensive task weighed respectively in the final marks. The guideline this evaluation system follows is that, in designing evaluation system, the major aim is to facilitate learning, instead of measuring the result.

\subsection{Data collection and analysis}

In order to answer the research questions, a survey of questionnaire and a semistructured interview were carried out. The data of learners' learning process and performance on the Zhihuishu platform were collected as supplementary evidence.

The questionnaire consisted of 41 items, which fall into 3 sections:

a) Students' perceptions and effects of BL approach with RISE support

b) Students' perceptions of resources, interaction, strategy and evaluation support

c) Suggestions and expectations

The items are statements for the respondent to indicate a level of agreement or disagreement using a 5-point Likert scale (1 - strongly disagree, 2 - disagree, 3 - not 
sure, 4 - agree and 5 - strongly agree). After a pilot survey and deletion of items with low reliability, the Cronbach's Alpha of the final questionnaire was 0.918, which indicates a high degree of internal-consistency reliability. Totally 87 students participated the survey and 83 effective questionnaires were collected.

The semi-structured interview was conducted with 12 participants chosen from all those 87 students, 4 randomly chosen from students with high learning achievement, 4 from the medium and 4 from those with low achievement. To ensure anonymity of the data, a number was assigned to each participant. For instance, the first participant was designated as S1. The interview encompassed 3 questions:

a) What do you think of the BL initiative with emphasis on support this term? Can you list any benefits or limitations?

b) What are your perceptions of the learning support measures (videos, pre-learning task lists, forum, one-to-one works doctor, teachers' guidance, etc.)?

c) Please offer suggestions for improvement of the BL support approach

After getting consent of the participants, the whole process was recorded and coded by two researchers in the team, who coded the interview independently and later on reached consensus after discussion.

\section{$3 \quad$ Findings and Discussion}

\subsection{Students' perceptions of the b-MOOC approach based on RISE support framework}

As what the data from the questionnaire shows in Table 1, the participants reported remarkable improvement in learners' autonomy, with mean scores of 4.25 . In the interview, 4 out of 12 participants referred to higher degree of autonomous learning. It coincides with the findings of previous studies [37-39], which found their students developed independent learning strategies and spent more time on tasks. Students also reported increase of interest (mean score of 3.79), acquisition of background knowledge (mean score of 3.92) and improvement of listening and speaking skills (mean score of 3.83). But they reported no remarkable improvement in the marks or academic achievement, with $48 \%$ of them choosing "not sure" item. It may be due to the short time of implementation, which can hardly bring immediate change in academic achievement. Additionally, students reported longer time devoted to the learning (mean score of 4.19). In the interview, 5 students mentioned that they need to watch the videos repeatedly to answer the questions on pre-learning task list. They would pause now and then to take notes and to fully comprehend the content delivered.

As to the perceptions on the BL approach with RISE support measures, 3 students in the interview said they like this approach, and 7 students referred to their various acquisition and improvement. S7 said that since it was her first BL experience, she felt at sea at the beginning. But following the thread of pre-learning task list and 
guided by the suggestion of learning strategy, she gradually got used to the new mode and learned to make good use of its strengths.

Table 1. Effects of the BL approach

\begin{tabular}{|l|c|c|c|}
\hline \multicolumn{1}{|c|}{ Title } & N & Mean & Std. Deviation \\
\hline 1. It helps in promoting interest in learning. & 83 & 3.795 & 0.838 \\
\hline 2. It helps in mastery of background knowledge. & 83 & 3.928 & 0.908 \\
\hline 3. It helps to improve reading and writing skills. & 83 & 3.482 & 0.929 \\
\hline 4. It helps to improve listening and speaking skills. & 83 & 3.831 & 1.034 \\
\hline 5. It helps to improve learning strategy. & 83 & 3.940 & 0.860 \\
\hline 6. It helps to enhance autonomous learning. & 83 & 4.253 & 0.839 \\
\hline 7. It helps to increase the marks. & 83 & 3.506 & 0.846 \\
\hline 8. It helps to develop critical thinking. & 83 & 3.542 & 0.941 \\
\hline 9. It helps to enhance ability in communication. & 83 & 3.699 & 0.972 \\
\hline 10. I can finish all the online learning tasks. & 83 & 3.964 & 0.956 \\
\hline 11. I devoted more time to the study of this subject. & 83 & 4.193 & 0.862 \\
\hline
\end{tabular}

\subsection{Feedback on elements of the support framework}

Feedback on resources support. As shown in Table 2, the pre-learning task list got high acceptance from students, with the 3 relating items getting mean scores of 4.25 , 4.27 and 4.27 respectively. The interview confirmed the perception with 10 out of 12 interviewees referring to the list as important support tool of learning. As what student S6 said, watching the videos with questions offered by the task list made her learning more targeted, and she got to know better the emphasis of the course. Previous study found that previewing upcoming assignments and learning activities can be useful indicators of a successful learning experience [40], and it is beneficial to construct the task-oriented environment supported by a well-designed structure that clearly guides students to solve given problems [19]. It can be concluded that pre-learning task list or other similar preparatory material facilitate greatly learning in BL context. As to the MOOC resources, there are also a large number of students from other higher education institutions choosing this course in Zhihuishu platform. Survey for feedback from the platform, with a much larger subject, showed that $78.7 \%$ students agree or strongly agree with the statement that the videos are of high quality and helped them a lot in their learning. For our own students, the items of "the online videos allowed me to learn the difficult content repeatedly" and "I will use the online videos when preparing for the final examination" got high mean scores of 4.08 and 4.02. Data from the platform shows that the average times of watching the different video clips range from 1.87 to 2.58 , indicating highly repeated watching. 
Table 2. Perception on resources

\begin{tabular}{|l|c|c|c|}
\hline \multicolumn{1}{|c|}{ Title } & N & Mean & $\begin{array}{c}\text { Std. } \\
\text { Deviation }\end{array}$ \\
\hline 12. The online videos allowed me to learn the difficult content repeatedly. & 83 & 4.084 & 0.900 \\
\hline $\begin{array}{l}\text { 13. I will use the online videos when preparing for the final examination. } \\
\text { 14. The pre-learning task list helped me make clear the method of online } \\
\text { learning. }\end{array}$ & 83 & 4.024 & 0.910 \\
\hline $\begin{array}{l}\text { 15. The pre-learning task list get me fully prepared for the BL. } \\
\text { 16. The pre-learning task list helped me in BL. }\end{array}$ & 83 & 4.253 & 0.713 \\
\hline
\end{tabular}

Feedback on interaction support: As shown in Table 3, of all the online and face-to-face interaction, students reported preference over and high appraisal on the Q\&A (question and answer) online discussion, group work and one-on-one comprehensive works doctor of face-to-face class, with mean scores of 4.03, 3.83 and 4.08 respectively. For online and group discussion, it's of vital importance to help set up learning communities and encourage them to collaborate in task completion [1]. The one-on-one comprehensive works doctor program got wide acceptance as highly individualized learning scaffolding.

Table 3. Perceptions on interaction

\begin{tabular}{|l|c|c|c|}
\hline \multicolumn{1}{|c|}{ Title } & N & Mean & Std. Deviation \\
\hline 17. It helps to promote teacher-student interaction. & 83 & 3.542 & 1.051 \\
\hline 18. It helps to promote peer interaction. & 83 & 3.795 & 0.985 \\
\hline 19. It helps to enhance ability in communication. & 83 & 3.699 & 0.972 \\
\hline 20. The comprehensive works doctor helped me in my study. & 83 & 4.087 & 1.011 \\
\hline 21. I'm willing to participate in Q\&A of the forum. & 83 & 3.590 & 1.082 \\
\hline 22. I acquired business knowledge in Q\&A. & 83 & 4.036 & 0.981 \\
\hline 23. I practiced language in the Q\&A of the forum. & 83 & 3.795 & 1.009 \\
\hline $\begin{array}{l}\text { 24. Group discussion in f2f class facilitates review and mastery of } \\
\text { knowledge. }\end{array}$ & 83 & 3.831 & 1.034 \\
\hline
\end{tabular}

Feedback on strategy support: Pre-learning task list acts also as a strategy guidance, for it shows clearly the structure of content delivered, the emphasis of learning and the detailed way to prepare for the online and face-to-face learning. Its effects were already discussed above. Item 5 of the questionnaire with statement of "it helps to improve learning strategy" got mean score of 3.94, indicating improved learning strategy. In the interview, 3 out of 12 participants referred to the continuous instruction of learning strategy as significant assistance to their adapting to the new BL approach.

Feedback on evaluation support: The participants' perception of the evaluation support is shown in Table 4. They agreed that the there're diversified methods of evaluation, with a high mean score of 4.205. Additionally, they value the function of various ways of evaluation in urging them to learn attentively, and 2 items relating to this got mean score of 3.84 and 4.09. The item of "the entrance test urged me to grasp the terms" got a very high mean score of 4.50 . It shows that the entrance test at the beginning of each face-to-face class strengthened effectively the terms they have 
learned online, which is beneficial as the mastery of specialized terms is the fundamental objective of the Business English course. In this way, it shows how the design of BL can influence the learning behavior of students. It is also found that frequent tests led to larger amount of reading and addressed the behavior of cheating in online learning [41].

Table 4. Perceptions of evaluation

\begin{tabular}{|l|c|c|c|}
\hline \multicolumn{1}{|c|}{ Title } & N & Mean & Std. Deviation \\
\hline 25. There are varied methods of evaluation. & 83 & 4.205 & 0.745 \\
\hline $\begin{array}{l}\text { 26. The varied evaluation online and offline urged me to learn this course } \\
\text { attentively. }\end{array}$ & 83 & 4.096 & 0.835 \\
\hline 27. The entrance test urged me to grasp the terms. & 83 & 4.506 & 0.592 \\
\hline 28. I joined discussion in forum to get the marks. & 83 & 3.602 & 0.869 \\
\hline 29. The study habit and interaction evaluation urged me to learn attentively. & 83 & 3.843 & 1.215 \\
\hline
\end{tabular}

\subsection{Expectations and suggestions}

There're 7 items and 1 open-end question in the questionnaire about expectations and suggestions. Data of the 7 items is shown in Table 5. Items 30, 31 and 32 show that the students agree or strongly agree with the statements that they need more teacher instruction, technical help and peer support. The reason may be that in the b-MOOC context the students face various challenges and sometimes feel confused, therefore they expect higher degree of support in various dimensions.

For the statement of "the pre-learning task list needs further improvement", the mean score is 3.723. In the interview, student $\mathrm{S} 1$ suggested more in-depth questions in the task list, saying the available ones are too simple, while student S9 complained that there were too many questions to answer. On one hand it shows the essential role the pre-learning task list plays in BL. Students use them frequently in every step of their learning and therefore they have higher expectation on it. On the other hand, the pre-learning task list can be improved by covering tasks of different levels of difficulty which are marked clearly so as to meet the individualized needs of students.

Table 5. Expectations and suggestions

\begin{tabular}{|l|c|c|c|}
\hline \multicolumn{1}{|c|}{ Title } & N & Mean & Std. Deviation \\
\hline 30. In BL I need more instruction from teacher. & 83 & 4.349 & 0.633 \\
\hline 31. In BL I need more technical assistance. & 83 & 3.928 & 0.762 \\
\hline 32. In BL I expect more peer support. & 83 & 3.807 & 0.981 \\
\hline 33. In BL I sometimes feel helpless and at sea. & 83 & 3.578 & 0.912 \\
\hline 34. The pre-learning task list needs improvement. & 83 & 3.723 & 0.754 \\
\hline 35. I expect more f2f class. & 83 & 3.855 & 0.939 \\
\hline
\end{tabular}

About the preference in the online and face-to-face section, item 35 of "I expect more face-to-face class" got mean score of 3.855. Also, in the interview, 4 students held the idea that they liked the BL approach while they expect more face-to-face class hours. To combine these findings with those on the online resources referred to 
above, conclusion can be reached that the participants recognize positively the role of online learning in BL, while at the same time they expect more face-to-face interaction. A number of studies found similar results of students' preference of face-to-face instruction [42-43]. The reason may be that it brings students clearer instruction and immediate feedback. Therefore, it can be suggested that the proportion of face-to-face section should be no less than the online part in BL design. Additionally, the online section calls for more targeted support.

\section{Conclusion}

Learning support proves to be essential in b-MOOCs practice but gets little research attention before. This study, aiming at achieving higher degree of active learning, constructed a RISE learning support framework which consists of four components including resources, interaction, strategy and evaluation support. It was put into teaching practice of Business English course. Questionnaires, semi-structured interview were conducted, supplemented by process and result data from the MOOC platform, to examine students' perceptions of and the effects of the framework and its four components, and to collect feedback and suggestions. Conclusions are reached in the following 3 aspects. (a) The RISE framework for b-MOOC got recognition from students and performed various functions, including promoting learning autonomy, improving learning strategy and increasing interaction and time devoted. But no obvious effect of improving academic achievement of students was observed. (b) In terms of the resources support, the MOOCs constructed by the teaching team of this course supported effectively the learning of students. The pre-learning task list got wide acceptance of the students, supporting them to conduct structured, targeted learning as well as connecting online and face-to-face sections seamlessly. For the component of interaction, various forms of online and offline interaction including forum discussion, one-on-one comprehensive works doctor and group discussion facilitated the engagement and active learning of learners. In terms of strategy support, the prelearning task list, the orientation section and the continuous guidance during the whole term helped a lot in learning strategy formation and improvement. The diversified evaluation methods urged effectively students to learn attentively in set pace, among which the entrance test got high recognition and the study habit marks and interaction marks also functioned effectively. (c) There's high need from students for different forms of support, especially those from the instructors and the frequently used guidance materials are expected to be more individualized. Additionally, students' preference over face-to-face instruction indicates that the proportion of face-toface section should be no less than the online part in BL design and the online section calls for more targeted support. It's hoped that these findings will offer practical reference for the design of support system and benefit the practice of b-MOOC.

There also existed limitation in this study. Because of limited timeframe, we did not organize standardized pre-test and post-test and so failed to measure the difference in students' academic achievement before and after the initiative. 
To conclude, the BL based on MOOCs calls for instructors to offer ongoing learning support to the students. Additionally, informed by the exploration of best practices of blended learning, a step further can be taken to find out common principles for learning support, and to explore what are the best practices of learning support under different circumstances.

\section{$5 \quad$ Acknowledgment}

This research is supported by the Shandong Social Science Planning Project (No.19CWZJ39).

\section{References}

[1] Garrison, D. R., \& Kanuka, H. (2004). Blended learning: Uncovering its transformative potential in higher education. The internet and higher education, 7(2), 95-105. https://doi. org/10.1016/j.iheduc.2004.02.001

[2] Alhusban, N., \& Shorman, S. (2020). Perceptions of Syrian Student Refugees towards Blended Learning: Implications for Higher Education Institutions. International Journal of Emerging Technologies in Learning (ijet), 15(01), 45-60. https://doi.org/10.3991/ijet.v15i $\underline{01.11431}$

[3] Johnson, L., Becker, S.A., Cummins, M., Estrada, V., Freeman, A. and Hall, C. (2013), NMC Horizon Report: 2013 Higher Education Edition, The New Media Consortium, Austin, TX, available at: www.nmc.org/system/files/pubs/1360189731/2013-horizon-reportHE.pdf (accessed 11 June 2014).

[4] Kukulska, A., \& Shield, L. (2008). An overview of mobile assisted language learning: From content delivery to supported collaboration and interaction. Re CALL: The Journal of EUROCALL, 20(3), 271-289. https://doi.org/10.1017/S0958344008000335

[5] Daniel, J. (2012). Making sense of MOOCs: Musings in a maze of myth, paradox and possibility Seoul: Korean National Open University. https://doi.org/10.5334/2012-18

[6] Torres-Coronas, T., \& Vidal-Blasco, M. A. (2018). MOOC and blended learning models: Analysis from a stakeholders' perspective. In Online Course Management: Concepts, Methodologies, Tools, and Applications (pp. 276-288). https://doi.org/10.4018/978-1$\underline{5225-5472-1 . \operatorname{ch} 015}$

[7] Sandeen, C. (2013). Integrating MOOCs into traditional higher education: The emerging "MOOC 3.0" era. Change: The magazine of higher learning, 45(6), 34-39. https://doi.org/ $\underline{10.1080 / 00091383.2013 .842103}$

[8] Yousef, A. M. F., Chatti, M. A., Schroeder, U., \& Wosnitza, M. (2015). A usability evaluation of a blended MOOC environment: An experimental case study. International Review of Research in Open and Distributed Learning, 16(2), 69-93. https://doi.org/10.191 73/irrodl.v16i2.2032

[9] Ronkowitz, K., \& Ronkowitz, L. C. (2015). MOOCs: Evolution and revolution. In MacroLevel Learning through Massive Open Online Courses (MOOCs): Strategies and Predictions for the Future (pp. 183-211). IGI Global. https://doi.org/10.4018/978-1-4666-83242.ch011 
[10] Berrett, D. (2012). How 'flipping' the classroom can improve the traditional lecture. The chronicle of higher education, 12(19), 1-3.

[11] Graham, C. R., Allen, S., \& Ure, D. (2005). Benefits and challenges of blended learning environments. In M. Khosrow-Pour (Ed.), Encyclopedia of information science and technology (pp. 253-259). https://doi.org/10.4018/978-1-59140-553-5.ch047

[12] Graham, C. R., Woodfield, W. \& Harrison, J. B. (2013) A framework for institutional adoption and implementation of blended learning in higher education, The Internet and Higher Education, vol. 18, pp. 4-14. https://doi.org/10.1016/j.iheduc.2012.09.003

[13] Dziuban, C., Hartman, J., Juge, F., Moskal, P. \& Sorg, S. (2006). Blended learning enters the mainstream. In C. J. Bonk \& C. R. Graham (Eds), The handbook of blended learning: Global perspectives, local designs (pp. 195-208). San Francisco, CA: Pfeiffer Publishing. https://doi.org/10.5465/amle.2008.31413871

[14] Adekola, J., Dale, V. H., \& Gardiner, K. (2017). Development of an institutional framework to guide transitions into enhanced blended learning in higher education. Research in Learning Technology, 25. https://doi.org/10.25304/rlt.v25.1973

[15] Ellis, R.A. (2014). Quality experiences of inquiry in blended contexts - university student approaches to inquiry, technologies, and conceptions of learning. Australasian Journal of Educational Technology, 30(3), 273-283. https://doi.org/10.14742/ajet.522

[16] Senn, G. J. (2008). Comparison of face-to-face and hybrid delivery of a course that requires technology skills development. Journal of Information Technology Education, 7, 267-283. Retrieved from http://jite.org/documents/Vol7/JITEv7p267-283Senn309.pdf. https://doi.org/10.28945/189

[17] Mendieta Aguilar, J. A. (2012). Blended learning and the language teacher: a literature review. Colombian Applied Linguistics Journal, 14(2), 163-180. ISSN 0123-4641. https:// doi.org/10.14483/udistrital.jour.calj.2012.2.a10

[18] Roslina, A. T., Nur Shaminah, M. K., \& Sian-Hoon, T. (2013). Students' Satisfaction on Blended Learning: A Preliminary Study. Pertanika Journal of Social Sciences \& Humanities, 21(3).

[19] Strayer, J. F. (2012). How learning in an inverted classroom influences cooperation, innovation and task orientation. Learning Environments Research, 15(2), 171-193. https://doi. org/10.1007/s10984-012-9108-4.

[20] Halverson, L. R., Graham, C. R., Spring, K. J., Drysdale, J. S., \& Henrie, C. R. (2014). A thematic analysis of the most highly cited scholarship in the first decade of blended learning research. The Internet and Higher Education, 20, 20-34. https://doi.org/10.1016/j.ihed $\underline{\text { uc.2013.09.004 }}$

[21] Wang, Y., Han, X., \& Yang, J. (2015). Revisiting the blended learning literature: Using a complex adaptive systems framework. Journal of Educational Technology \& Society, 18(2), 380-393. https://www.jstor.org/stable/jeductechsoci.18.2.380

[22] Dringus, L. P., and A. B. Seagull. 2015. A five-year study of sustaining blended learning initiatives to enhance academic engagement in computer and information sciences campus courses. In Blended learning: Research perspectives. Vol. 2. Edited by A. G. Picciano, C. D. Dziuban, and C. R. Graham, 122-140. New York: Routledge.

[23] Robinson, B. (1995). LEARNER SUPPORT. Open and distance learning today, 221.

[24] Tait, A. (2000). Planning student support for open and distance learning. Open Learning, 15(3), 287-299. https://doi.org/10.1080/713688410 
[25] Van Laer, S., \& Elen, J. (2017). In search of attributes that support self-regulation in blended learning environments. Education and Information Technologies, 22(4), 13951454. https://doi.org/10.1007/s10639-016-9505-x

[26] Nortvig, A. M., Petersen, A. K., \& Balle, S. H. (2018). A Literature Review of the Factors Influencing E-Learning and Blended Learning in Relation to Learning Outcome, Student Satisfaction and Engagement. Electronic Journal of E-learning, 16(1), 46-55. Available online at www.ejel.org

[27] Mirriahi, N., Alonzo, D., \& Fox, B. (2015). A blended learning framework for curriculum design and professional development. Research in Learning Technology, 23. https://doi. org/10.3402/rlt.v23.28451

[28] Fransen, K., Boen, F., Vansteenkiste, M., Mertens, N., \& Vande Broek, G. (2018). The power of competence support: The impact of coaches and athlete leaders on intrinsic motivation and performance. Scandinavian Journal of Medicine \& Science in Sports, 28, 725745. https://doi.org/10.1111/sms.12950

[29] Moskal, P., Dziuban, P., \& Hartman, J. (2013). Blended learning: A dangerous idea? The Internet and Higher Education, 18, 15-23. https://doi.org/10.1016/j.iheduc.2012.12.001

[30] You, H. W. (2019). Students' Perception about Learning using MOOC. International Journal of Emerging Technologies in Learning (ijet), 14(18), 203-208. https://doi.org/10.3991/ ijet.v14i18.10802

[31] Osguthorpe, R.T. and C. R. Graham. (2003). Blended learning environments: definitions and directions. Quarterly Review of Distance Education 4/3: 227-33. Retrieved March 9, 2020 from https://www.learntechlib.org/p/97576/.

[32] Vygotsky, L. S. (1978). Mind in the society: The development of higher psychological processes. Cambridge: Harvard University Press.

[33] Garrison, D R. (2009). Communities of inquiry in online learning. In P. L. Rogers (Ed.), Encyclopedia of distance learning, pp. 352-355, 2nd ed. Hershey, PA: IGI Global. https ://doi.org/10.4018/978-1-60566-198-8.ch052

[34] Barnard, L., Lan, WY., To, Y M., Paton, VO., Lai, S. (2009) Measuring self-regulation in online and blended learning environments. Internet and Higher Education, vol.12, no.1, pp. 1-6. https://doi.org/10.1016/j.iheduc.2008.10.005

[35] DeLozier, S. J., \& Rhodes, M. G. (2017). Flipped classrooms: a review of key ideas and recommendations for practice. Educational Psychology Review, 29(1), 141-151. https:// doi.org/10.1007/s10648-015-9356-9

[36] Helen; Sharpe Beetham, Beetham, H., \& Sharpe, R. (2007). Rethinking pedagogy for a digital age (p. 10001). London: routledge. https://doi.org/10.4324/9781351252805-22

[37] Banditvilai, C. (2016). Enhancing Students' Language Skills through Blended Learning. Electronic Journal of e-Learning, 14(3), 220-229. ) available online at www.ejel.org

[38] McLean, S., Attardi, S. M., Faden, L., \& Goldszmidt, M. (2016). Flipped classrooms and student learning: not just surface gains. Advances in physiology education, 40(1), 47-55. https://doi.org/10.1152/advan.00098.2015

[39] Gao, B. (2019). Highly Efficient English MOOC Teaching Model Based on Frontline Education Analysis. International Journal of Emerging Technologies in Learning (ijet), 14(06), 138-146. https://doi.org/10.3991/ijet.v14.i06.10160 
[40] Kim, M. K., Kim, S. M., Khera, O., \& Getman, J. (2014). The experience of three flipped classrooms in an urban university: an exploration of design principles. The Internet and Higher Education, 22, 37-50. https://doi.org/10.1016/j.iheduc.2014.04.003

[41] Rayyan, S., Fredericks, C., Colvin, K. F., Liu, A., Teodorescu, R., Barrantes, A. \& Pritchard, D. E. (2016). A MOOC based on blended pedagogy. Journal of Computer Assisted Learning, 32(3), 190-201. https://doi.org/10.1111/jcal.12126

[42] Hanson, K. S. \& Clem, F. A. (2005). To blend or not to blend: A look at community development via blended learning strategies. In C. J. Bonk \& C. R. Graham, The handbook of blended learning: Global perspectives, local designs (pp. 136-150). New York, NY: Pfeiffer \& Company.

[43] Chandra V. and Fisher D. L., (2009), Students' perceptions of a blended web-based learning environment, Learn. Environ. Res., 12(1), 31-44. https://doi.org/10.1007/s10984-008$\underline{9051-6}$

\section{$7 \quad$ Authors}

Shurong Zhao works as a professor at School of Foreign Languages at Shandong Women's University, Daxue Rd. 2399, 250300, Jinan, China, email: cathy@sdwu.edu.cn.

Junxia Song works at School of Foreign Languages at Shandong Women's University, Daxue Rd. 2399, 250300, Jinan, China, email: rebeccasong@ sdwu.edu.cn.

Article submitted 2020-07-19. Resubmitted 2020-09-02. Final acceptance 2020-09-02. Final version published as submitted by the authors. 